\title{
Male Breast Cancer; A Review of Risk Factors and Clinical and Radiological Features
}

\author{
Maryam Jafari ${ }^{1{ }^{*}}$, Asieh Olfatbakhsh ${ }^{1}$, Kiara Rezaei-kalantari ${ }^{2}$ \\ ${ }^{1}$ Breast Diseases Department, Breast Cancer Research Center, Motamed Cancer \\ Institute, ACECR, Tehran, Iran \\ ${ }^{2}$ Rajaie Cardiovascular Medical and Research Center,Iran University of Medical \\ Sciences,Tehran,Iran \\ * Corresponding author: Maryam Jafari, Breast Diseases Department, Breast Cancer \\ Research Center, Motamed Cancer Institute, ACECR, Tehran, Iran. E-mail: maryjafa- \\ rimd@gmail.com
}

DOI: $10.21859 / \mathrm{mci}-01044$

Submitted: 2 August 2017

Revised: 27 August 2017

Accepted: 20 September 2017

ePublished: 1 October 2017

Keywords:

Breast Neoplasms

Male

Mammography

Ultrasonography

\begin{abstract}
While male breast cancer (MBC) consists only $1 \%$ of all breast cancers in the United States, approximately 2000 men are diagnosed annually and the incidence seems to be slowly increasing. About $50 \%$ of men have axillary nodal metastasis at the time of diagnosis. A mean delay of 6 to 10 months occurs in the diagnosis of MBC, which leads to the progression of the disease before presentation. More than $40 \%$ of MBCs present with stage III/IV disease. Therefore, men with MBC have a worse prognosis compared with women. Additionally, as a result of the paucity of breast tissue in males, early chest wall spread occurs. Therefore, it seems that recognition of the symptoms and radiologic features of $\mathrm{MBC}$ can improve early detection, the prognosis and survival rate of the disease. A few researches focused on male breast cancer; however, there are many similarities with female breast cancer and some differences. The current study aimed to review the latest information on risk factors, clinical, and radiological features of MBC.
\end{abstract}

(C) 2017. Multidisciplinary Cancer Investigation

\section{INTRODUCTION}

Over the last 2 decades, the rate of male breast complaints increased from $0.8 \%$ to $2.4 \%$, while $1 \%$ of all breast cancers occur in men [1]. In 2017, about 2470 men were diagnosed with the disease in America [2]. The femaleto-male breast cancer ratio is 70-100:1 [3]. The mean age at the time of diagnosis in men is 67 years, which is about 5 to 10 years higher than that of women. Usually, male breast cancer (MBC) is detected in more advanced stages because of delayed diagnosis, compared with that of the women and about $50 \%$ of men have axillary nodal metastasis at the time of diagnosis [4]; therefore, early detection of MBC could improve the survival rate and prognosis of the disease [5]. The current study aimed to review the manifestations, imaging, and pathologic features of the breast cancers in men.

\section{Male Breast Anatomy}

The rudimentary mammary glands are composed of mammary lobes that drain via lactiferous ducts into the nipple [6]. During the peripubertal period in young males, atrophy of the ducts usually happens after a significant increase in the testosterone level (about 30 folds) [7] and despite the young females, no estrogen or progesterone stimulates the ductal proliferation and branching. Some- times at the onset of puberty, serum estradiol transiently increased and may cause mild proliferation of sub-areolar ducts and stroma, which resolves spontaneously, due to the consequential increase of the testosterone level [8].

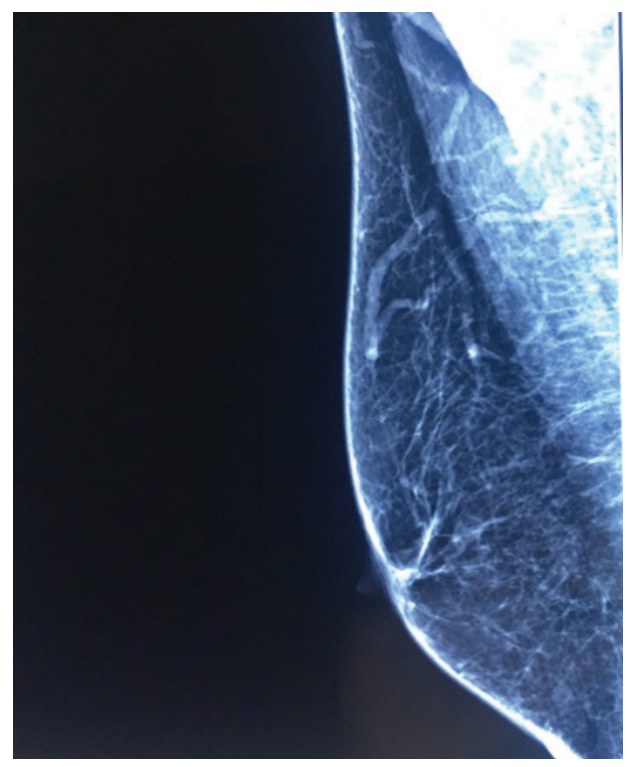

Figure 1: A Normal Male Breast Mammogram with a Fatty Tissue and Stromal Components. 
Table 1: Clinical Features of Gynecomastia Versus Male Breast Carcinoma

\begin{tabular}{lcc}
\hline Features & Gynecomastia & Breast Carcinoma \\
\hline Patient's Age & $\begin{array}{c}\text { Bimodal prevalence: peripuber- } \\
\text { tal and }>50 \text { years }\end{array}$ & $>60$ years \\
Clinical Manifestations & Soft tender mass; mobile mass & Soft or firm non-tender mass; mobile or non-mobile mass \\
Relationship of Lesion to the Nipple & Central, sub-areolar area & Eccentric, subareolar area \\
\hline Laterality & Most commonly bilateral & Usually unilateral \\
\hline
\end{tabular}

Normal breast in adult males is composed of skin, subcutaneous fat, atrophic ducts, and stromal elements, which in mammography could be observed as homogeneously and almost fatty tissue, which could be observed in Figure 1.

In the male breast tissue, there are no Cooper ligaments. Breast lobular development is extremely uncommon in men and pathologies such as fibroadenoma, phyllodes tumor, invasive lobular carcinoma, carcinosarcoma, and lobular carcinoma in situ related to lobular proliferation are rare. On the other hand, gynecomastia, invasive ductal carcinoma, ductal carcinoma in situ, and papillary neoplasm, conditions related to ductal and stroma proliferation may manifest in men $[9,10]$.

\section{Risk Factors}

As shown in Table 1, the two common and well-established risk factors for MBC include genetic factors (such as a positive family history especially first-degree male or female relatives, $B R C A 2$ and $B R C A 1$ mutations, and a family history of prostate cancer) and conditions associated with an abnormal estrogen-to-androgen ratio and hyperestrogenism (e. g, the Klinefelter syndrome, exogenous estrogen or testosterone use, obesity, orchitis/epididymitis, and finasteride use). Other factors are related to lifestyle (e.g, lack of exercise) and X-ray exposure such as chest radiation [11].

Genetic risk factors such as androgen receptor, $\mathrm{CYP} 17$ (cytochrome P450 17A1) and CHEK2 (checkpoint kinase 2) are possible factors for MBCs. Another probable risk factor is long exposure to electromagnetic fields or heat. It is proposed that some chemicals increase the risks, and the most important ones are volatile organic compounds (e. g, tetrachloroethylene, perchloroethylene, trichloroethylene, dichloroethylene, and benzene) [11]. About $80 \%$ of MBCs are infiltrating ductal carcinoma (IDC) histologically [12]; $85 \%$ to $95 \%$ of the cases are not otherwise specified (NOS) and in about $35 \%$ to $50 \%$ associated with in situ component. Most of DCIS are high grade form. Pure DCIS occurs in 7\% to $11 \%$ of the cases, usually low to intermediate grades $[13,14]$. Other less common subtypes are inflammatory carcinoma and invasive papillary carcinoma, respectively [15]. Papillary carcinomas are relatively more common in males, and lobular carcinomas are rare in men compared with women [16]. Lobular carcinoma may be observed in the Klinefelter syndrome or other states of excess estrogen. Finally, metastasis from other sites is extremely rare in men [17]. Another malignant condition that rarely affects the male breast is lymphoma, which usually manifests as multiple enlarged axillary lymph nodes and no definite breast mass; $44 \%$ of them are primary lymphoma [18]. Another infrequent tumor is dermatofibrosarcoma also called spindle cell tumor, which is more common in males than females and usually occurs in the age range of 20 to 50 years. A high rate of local recurrence after surgical excision is observed; therefore, complete resection should be performed [19]. The vast majority of MBCs are hormonally sensitive and estrogen/progesterone-receptor positive in $65 \%$ to $85 \%$. In some studies, HER 2 overexpression is $2 \%$ to $42 \%$ [20-25]. There were controversies about $p 53$ mutation in the earlier studies; some of them suggested that $\mathrm{MBC}$ were more likely to be p53-negative and in some studies MBCs were similar to those of women and mostly p53-positive [26].

\section{Male Breast Cancer Manifestations}

The most common symptom/sign is a painless palpable mass. Others consist nipple discharge, ulceration, retraction, skin thickening, and palpable axillary lymph nodes [17]. The Paget's disease of the nipple is more common, compared with women [27]. The most common clinical differential diagnosis of $\mathrm{MBC}$ is gynecomastia in some clinical points, which can help to diagnose as shown in Table $1[28]$.

\section{Imaging Protocols}

The incidence of breast cancer is low enough in male patients which routine screening mammography is not recommended. Therefore, all imaging modalities of the male breast are in the diagnostic manner [10]. Bilateral craniocaudal (CC) and mediolateral oblique view mammograms are the initial modalities for imaging of men with clinical breast findings, despite the relatively small size of the male breast. Sometimes supplemental views such as reverse CC or magnification, spot compression, or tangential view could be helpful [29]. If mammography showed suspicious findings, then, ultrasound (US) is helpful and accurate to evaluate the breast lesions [30]. Performing US with a high-frequency transducer is more sensitive to assess deep portions not accessible on mammograms [10]. Mammography-guided biopsy could not be performed due to the small size of the male breast. The US-guided biopsy is completely preferable [31]. 


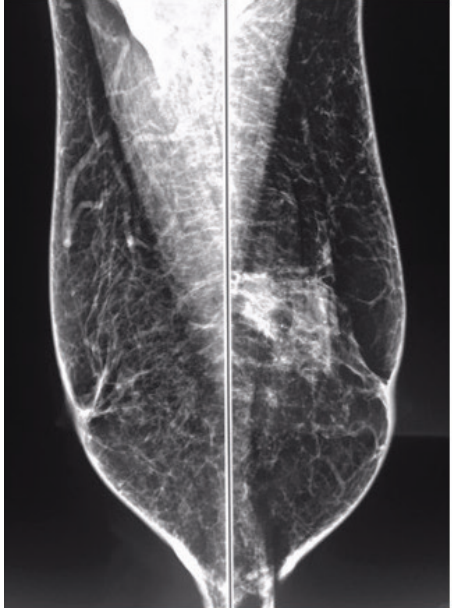

A

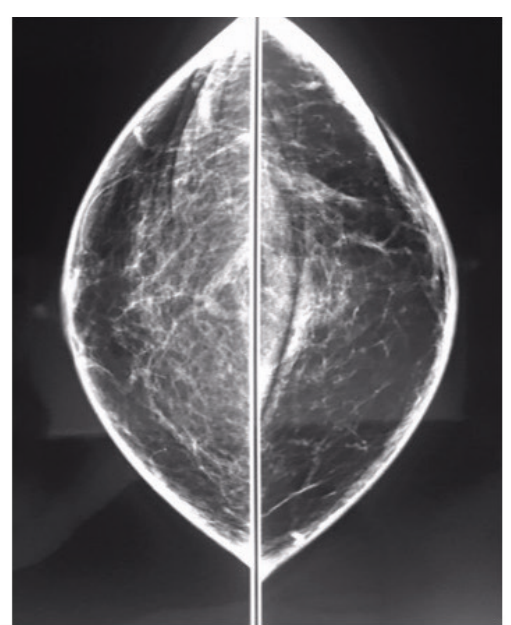

B

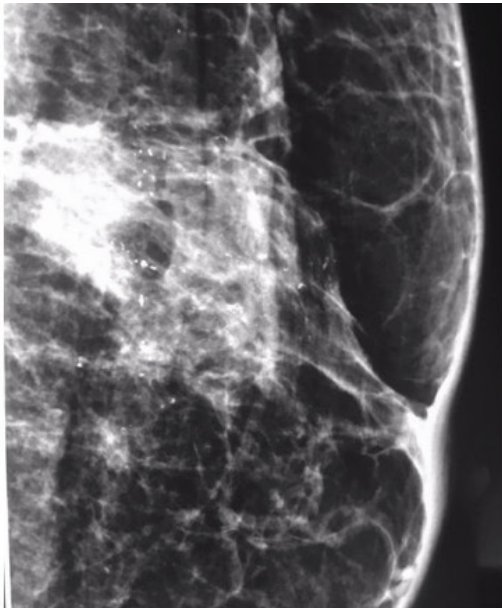

C

Figure 2: Mammograms Obtained in a 74-year-old Man with the Chief Complaint of Left-sided Nipple Discharge. $\mathrm{A}$ and $\mathrm{B}$, mediolateral oblique and craniocaudal views show a focal asymmetry in left upper part with segmentally distributed mainly coarse heterogeneous suspicious appearing microcalcifications. C, magnification view demonstrates morphology of the microcalcifications. histopathologic analysis revealed infiltrating ductal carcinoma and ductal carcinoma in situ.

\section{Mammographic Appearance}

Male breast cancer mostly occurs in a sub-areolar region, but it is usually eccentric to the nipple. The shapes of the lesions may be round, oval, or irregular. The mass border is circumscribed, indistinct, or mostly spiculated and microlobulated. The typical form of them in the mammogram is a high-density circumscribed irregularly shaped mass. Calcifications are rare and tend to be fewer in number, coarser, and less frequently rodshaped (Figure 2).

Other associated features are skin thickening, nipple retraction, and axillary lymphadenopathy, which carry a poor prognosis [10,30-32]. Secondary signs of breast cancer such as nipple retraction, increased breast trabeculation and skin thickening occur earlier in male, which can be easily detected in the mammogram [33].

\section{Ultrasound Features}

The US features of MBC are similar in women. In case of series, the most invasive cancers are non-parallel and hypoechoic masses with angulated, and microlobulatedor spiculated margins. In different studies, posterior acoustic features are variable in malignant lesions [10]. The US of the axillary region should be routinely performed. Enlarged axillary lymph nodes can be easily observed in US evaluation. The most common causes of unilateral axillary lymph node enlargement are due to benign conditions such as reactive hyperplasia, infection, or granulomatous disease. The causes of malignant lymph nodes are mostly due to lymphoma and metastatic disease from breast cancer, lung cancer, melanoma, and squamous cell cancer [34]. The sonographic features of pathologic lymph nodes include the cortical thickness in excess of $3 \mathrm{~mm}$, eccentric thickening, irregular margins and encroachment on displacement of the fatty hilum or suspicious vascularity in Doppler evaluation (e. g, extra-hilar flow) [35]. Some investigators demonstrated that most of the complex (cystic-solid) male breast masses were papillary ductal carcinoma in situ in histopathologic results. Therefore, cystic-solid masses detected at sonography of a male patient warrant a biopsy [36].

\section{Magnetic Resonance Imaging Features}

There are a few studies in this case. However, potential applications of magnetic resonance imaging (MRI) include lesion demonstration in the patient with gynecomastia, improvement of diagnosis of chest-wall invasion and mostly in equivocal cases [37]. Although MRI is technically difficult, it could be helpful in some patients. Suspicious features of lesions in MBC are the same as those of females, which consist spiculated margins, washout enhancement kinetics, and abnormal lymphadenopathy [38].

\section{Differential Diagnosis}

The most common disease of male breast (up to 65\%) is gynecomastia, which usually manifests as a mobile tender sub-areolar mass within the age range of 50 to 80 years and may be tender in the acute phase. Gynecomastia shows three mammographic patterns including three imaging patterns as follows: nodular glandular, dendritic (chronic fibrotic phase), and diffuse glandular. Gynecomastia usually, in mammographic images, shows an indistinct border (Figure 3) [1, 7]. 


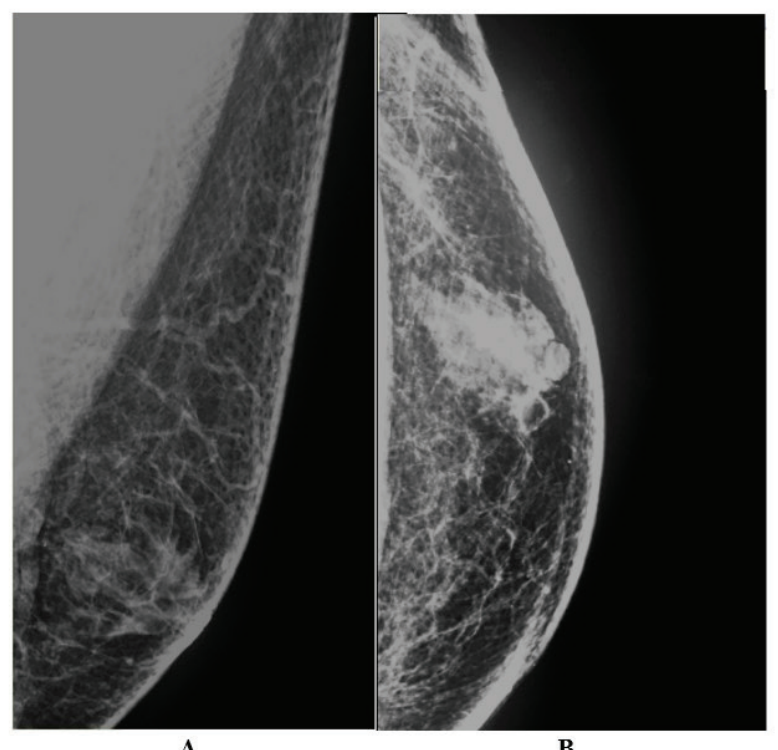

$\mathbf{A}$

Figure 3: Mammograms in a 62-year-old Man with the Chief Complaint of Left-sided Tender Mass Were Performed.

$\mathrm{A}$ and $\mathrm{B}$, mediolateral oblique and craniocaudal views show fibro glandular tissue in left retoareolar region, which is compatible with gynecomastia.

Another differential diagnosis is pseudogynecomastia, which is usually bilateral with no palpable mass. It results from excessive fat deposition associated with obesity [33]. Another differential diagnosis are mastitis and abscess formation, which are not common in males compared with females $[39,40]$ and manifest as fever, tenderness, erythema, and skin thickening [39]. Mammography shows trabecular and skin thickening along with breast enlargement; sometimes it is difficult to differentiate breast infection from cancer [33, 40]. Fat necrosis, which develops after trauma, could represent as a tender mass with or without calcification. On mammographic images, it can be observed as a density with calcification or a radiolucent mass [7]. However, it sometimes mimics cancer [28]. One of the frequent masses in the male breast is inclusion cyst [41], which may or may not be accompanied by tenderness. They are typically small, subcutaneous, well-defined masses on mammography [7]. Sometime the cysts rupture and following the induced inflammatory reaction cause irregular borders on mammogram, which is similar to malignancy [42]. Long-standing type 1 diabetes inflammatory process of breast disease may cause diabetic mastopathy, which can be observed as a mass or asymmetry on mammogram $[43,44]$. Differentiation from cancer is often difficult clinically and mammographically $[45,46]$ and biopsy is usually needed for definitive diagnosis.

\section{Outcome and Prognosis}

The overall prognosis of MBC tends to be worse than that of female, which may be due to poor awareness

of the disease and diagnostic delays and hence, higher stages of tumors at the time of diagnosis. Despite women, younger age does not appear to correlate with worse prognosis in men. Black men and the ones living in non-metropolitan areas seem to fare poorly. In prior studies, breast cancer-related death was more common in unmarried males than married ones [4, 11]. These tumors are more likely to be node-positive and show lymphovascular invasion and nipple involvement, compared with female tumors $[47,48]$. Axillary lymph node status is an important prognostic factor, similar to those of women [11]. Tumor grade is another powerful prognostic factor in males, similar to that of women. In men, the relationship between HER2 status and overall survival rate is controversial. It is not proved that progesterone receptor status and lymphovascular invasion affect the prognosis in men [11]. One recent study reported that high-grade tumor, progesterone-receptor-negative tumors, and HER2-negative ones, as well as males with positive $B R C A 2$ mutations were associated with poorer prognosis $[11,49]$. In another study, patients with stage IV of MBCs had poor prognosis if they had PR-positive receptors, younger age ( $\leq 65$ years), and tumor size $\leq$ $2 \mathrm{~cm}$ or the history of surgery [50]. Although the majority of male breast complaints are benign in the final assessment, however, radiologists' role to distinguish suspicious-appearing masses and warrant biopsy is inevitable. There is no routine screening imaging method in the males with no chief complaint and all imaging modalities are diagnostic tools to detect lesions, unlike females. Initially, according to breast exam, all clinically suspicious lesions should be referred for imaging and evaluated with mammography at first. The current study was an accurate study to diagnose benign lesions such as gynecomastia vs. cancer. To evaluate the contralateral breast, bilateral mammograms should always be obtained [33]. The US is often used for further characterization of questionable findings in the mammogram. Routine evaluation of axillary regions is recommended by US, due to the high prevalence of lymph node metastasis in MBC (about 50\%).Cystic lesions, especially complex ones, should be further evaluated by tissue diagnosis due to the potential risk of breast cancer. When a lesion appears suspicious in imaging, the preferable method for biopsy is the US-guided core needle biopsy.

\section{ACKNOWLEDGMENTS}

This research was supported by Breast cancer Research Center, Motamed Cancer Institute. We would like to thank Prof. Keyvan Majidzadeh for the patient guidance and encouragement.

\section{CONFLICT OF INTEREST}

The authors declared no conflict of interest. 


\section{ETHICS APPROVAL}

Not Applicable.

\section{REFERENCES}

1. Şafak KY. Mammography Findings of Male Breast Diseases. The Journal of Breast Health. 2015;11(3):106-10. DOI: 10.5152/tjbh.2015.2565 PMID: PMC5351447

2. Society AC. Breast Cancer Facts \& Figures 2017 [updated 2017; cited 2017]. Available from: https://www.cancer.org/ research/cancer-facts-statistics/breast-cancer-facts-figures. html.

3. Giordano SH. A review of the diagnosis and management of male breast cancer. Oncologist. 2005;10(7):471-9. DOI: 10.1634/theoncologist.10-7-471 PMID: 16079314

4. Cutuli B, Le-Nir CC, Serin D, Kirova Y, Gaci Z, Lemanski C, et al. Male breast cancer. Evolution of treatment and prognostic factors. Analysis of 489 cases. Crit Rev Oncol Hematol. 2010;73(3):246-54. DOI: 10.1016/j.critrevonc.2009.04.002 PMID: 19442535

5. Erhan Y, Zekioglu O, Erhan Y. Invasive lobular carcinoma of the male breast. Canadian Journal of Surgery. 2006;49(5):3656. PMID: PMC3207588

6. Al-Obaidi S, Hussein H, Awazli L, Tajer S. Review of Male Breast Disorder in Medical City. J Fac Med Baghdad. 2011;53:371-6.

7. Iuanow E, Kettler M, Slanetz PJ. Spectrum of disease in the male breast. AJR Am J Roentgenol. 2011;196(3):W247-59. DOI: $10.2214 /$ AJR.09.3994 PMID: 21343472

8. Johnson RE,MuradMH.Gynecomastia: pathophysiology, evaluation, and management. Mayo Clin Proc. 2009;84(11):10105. DOI: 10.1016/S0025-6196(11)60671-X PMID: 19880691

9. Kopans DB. Breast Imaging: Lippincott Williams \& Wilkins; 2007.

10. Chen L, Chantra PK, Larsen LH, Barton P, Rohitopakarn M, Zhu EQ, et al. Imaging characteristics of malignant lesions of the male breast. Radiographics. 2006;26(4):993-1006. DOI: 10.1148/rg.264055116 PMID: 16844928

11. Ruddy KJ, Winer EP. Male breast cancer: risk factors, biology, diagnosis, treatment, and survivorship. Ann Oncol. 2013;24(6):1434-43. DOI: 10.1093/annonc/mdt025 PMID: 23425944

12. Giordano SH, Buzdar AU, Hortobagyi GN. Breast cancer in men. Ann Intern Med. 2002;137(8):678-87. PMID: 12379069

13. Brents M, Hancock J. Ductal Carcinoma In situ of the Male Breast. Breast Care (Basel). 2016;11(4):288-90. DOI: 10.1159/000447768 PMID: 27721718

14. Leinung S, Horn LC, Backe J. [Male breast cancer: history, epidemiology, genetic and histopathology]. Zentralbl Chir. 2007;132(5):379-85. DOI: $10.1055 / \mathrm{s}-2007-981260$ PMID: 17907078

15. Anderson WF, Jatoi I, Tse J, Rosenberg PS. Male Breast Cancer: A Population-Based Comparison With Female Breast Cancer. Journal of Clinical Oncology. 2010;28(2):232-9. DOI: 10.1200/JCO.2009.23.8162 PMID: PMC2815713

16. Nahleh ZA, Srikantiah R, Safa M, Jazieh AR, Muhleman A, Komrokji R. Male breast cancer in the veterans affairs population: a comparative analysis. Cancer. 2007;109(8):1471-7. DOI: $10.1002 /$ cncr.22589 PMID: 17342768

17. Mathew J, Perkins GH, Stephens T, Middleton LP, Yang WT. Primary breast cancer in men: clinical, imaging, and pathologic findings in 57 patients. AJR Am J Roentgenol. 2008;191(6):1631-9. DOI: 10.2214/AJR.08.1076 PMID: $\underline{19020230}$

18. Domchek SM, Hecht JL, Fleming MD, Pinkus GS, Canellos GP. Lymphomas of the breast: primary and secondary involvement. Cancer. 2002;94(1):6-13. PMID: 11815954

19. Chang CK, Jacobs IA, Salti GI. Outcomes of surgery for dermatofibrosarcoma protuberans. Eur J Surg Oncol. 2004;30(3):341-5. DOI: 10.1016/j.ejso.2003.12.005 PMID: 15028319

20. Fox SB, Rogers S, Day CA, Underwood JC. Oestrogen receptor and epidermal growth factor receptor expression in male breast carcinoma. J Pathol. 1992;166(1):13-8. DOI: 10.1002/ path.1711660104 PMID: 1538271

21. Burga AM, Fadare O, Lininger RA, Tavassoli FA. Invasive carcinomas of the male breast: a morphologic study of the distribution of histologic subtypes and metastatic patterns in 778 cases. Virchows Archiv. 2006;449(5):507-12. DOI: 10.1007/ s00428-006-0305-3 PMID: PMC1888721

22. Cunha F, Andre S, Soares J. Morphology of male breast carcinoma in the evaluation of prognosis. Pathol Res Pract. 1990;186(6):745-50. DOI: 10.1016/S0344-0338(11)802657 PMID: 1964731

23. Jonasson JG, Agnarsson BA, Thorlacius S, Eyfjord JE, Tulinius $\mathrm{H}$. Male breast cancer in Iceland. Int J Cancer. $\quad 1996 ; 65(4): 446-9$. DOI: $10.1002 /($ SICI $) 1097-$ $\underline{0215(19960208) 65: 4<446:: A I D-I J C 9>3.0 . C O ; 2-X \quad \underline{\text { PMID: }}}$ 8621225

24. Tan PH, Sng IT. Male breast cancer: a retrospective study with immunohistochemical analysis of hormone receptor expression. Pathology. 1997;29(1):2-6. PMID: 9094169

25. Tahmasebi S, Akrami M, Omidvari S, Salehi A, Talei A. Male breast cancer; analysis of 58 cases in Shiraz, South of Iran. Breast Dis. 2010;31(1):29-32. DOI: 10.3233/BD-2009-0293 PMID: 20644250

26. Andre S, Pinto AE, Laranjeira C, Quaresma M, Soares J. Male and female breast cancer--differences in DNA ploidy, p21 and p53 expression reinforce the possibility of distinct pathways of oncogenesis. Pathobiology. 2007;74(6):323-7. DOI: 10.1159/000110025 PMID: 18087196

27. Karakas C. Paget's disease of the breast. Journal of Carcinogenesis. 2011; 10:31. DOI: 10.4103/1477-3163.90676 PMID: PMC3263015

28. Nguyen C, Kettler MD, Swirsky ME, Miller VI, Scott C, Krause $\mathrm{R}$, et al. Male breast disease: pictorial review with radiologic-pathologic correlation. Radiographics. 2013;33(3):763-79. DOI: $10.1148 /$ rg.333125137 PMID: 23674773

29. Garnett SE. Male Mammography. In: Hogg P, Kelly J, Mercer C, editors. Digital Mammography: A Holistic Approach. Cham: Springer International Publishing; 2015. p. 239-40.

30. Gunhan-Bilgen I, Bozkaya H, Ustun E, Memis A. Male breast disease: clinical, mammographic, and ultrasonographic features. Eur J Radiol. 2002;43(3):246-55. PMID: 12204407

31. Stavros AT, Ovid Technologies I. Breast ultrasound Philadelphia: Lippincott Williams \& Wilkins; 2004. Available from: http://ovidsp.ovid.com/ovidweb. cgi $? \mathrm{~T}=\mathrm{JS} \& \mathrm{NEWS}=\mathrm{n} \& \mathrm{CSC}=\mathrm{Y} \& \mathrm{PAGE}=$ booktext $\& \mathrm{D}=-$ books \&AN=01382451\$\&XATH=/PG(0).

32. Dershaw DD, Borgen PI, Deutch BM, Liberman L. Mammographic findings in men with breast cancer. AJR Am J Roentgenol. 1993;160(2):267-70. DOI: 10.2214/ajr.160.2.8424331 PMID: 8424331

33. Popli MB, Popli V, Bahl P, Solanki Y. Pictorial essay: Mammography of the male breast. The Indian Journal of Radiology \& Imaging. 2009;19(4):278-81. DOI: 10.4103/09713026.57207 PMID: PMC2797738

34. Sen F, Medeiros LJ, Lu D, Jones D, Lai R, Katz R, et al. Mantle cell lymphoma involving skin: cutaneous lesions may be the first manifestation of disease and tumors often have blastoid cytologic features. Am J Surg Pathol. 2002;26(10):1312-8. PMID: 12360046

35. Net JM, Mirpuri TM, Plaza MJ, Escobar CA, Whittington EE, Collado-Mesa F, et al. Resident and fellow education feature: US evaluation of axillary lymph nodes. Radiographics. 2014;34(7):1817-8. DOI: 10.1148/rg.347140081 PMID: 25384281

36. Yang WT, Whitman GJ, Yuen EH, Tse GM, Stelling CB. Sonographic features of primary breast cancer in men. AJR Am J Roentgenol. 2001;176(2):413-6. DOI: 10.2214/ ajr.176.2.1760413 PMID: 11159083

37. Shaw A, Smith B, Howlett D. Male breast carcinoma and the use of MRI. Radiol Case Rep. 2011;6(3):455. DOI: 10.2484/ rcr.v6i3.455 PMID: 27307904

38. Grimm LJ. Male Breast Cancer Imaging: Medscape; 2017 [updated Jun 12, 2017]. Available from: http://emedicine.medscape.com/article/345979-overview.

39. Draghi F, Tarantino CC, Madonia L, Ferrozzi G. Ultrasonography of the male breast. J Ultrasound. 2011;14(3):122-9. DOI: 
10.1016/j.jus.2011.06.004 PMID: 23397020

40. Scholefield JH, Duncan JL, Rogers K. Review of a hospital experience of breast abscesses. Br J Surg. 1987;74(6):469-70. PMID: 3607400

41. Yitta S, Singer CI, Toth HB, Mercado CL. Image presentation. Sonographic appearances of benign and malignant male breast disease with mammographic and pathologic correlation. J Ultrasound Med. 2010;29(6):931-47. PMID: 20498468

42. Cooper RA, Ramamurthy L. Epidermal inclusion cysts in the male breast. Can Assoc Radiol J. 1996;47(2):92-3. PMID: $\underline{8612091}$

43. Valdez R, Thorson J, Finn WG, Schnitzer B, Kleer CG. Lymphocytic mastitis and diabetic mastopathy: a molecular, immunophenotypic, and clinicopathologic evaluation of 11 cases. Mod Pathol. 2003;16(3):223-8. DOI: 10.1097/01. MP.0000056627.21128.74 PMID: 12640102

44. Kudva YC, Reynolds C, O’Brien T, Powell C, Oberg AL, Crotty TB. "Diabetic mastopathy," or sclerosing lymphocytic lobulitis, is strongly associated with type 1 diabetes. Diabetes Care. 2002;25(1):121-6. PMID: 11772912

45. Minkowitz S, Hedayati H, Hiller S, Gardner B. Fibrous mastopathy. A clinical histopathologic study. Cancer. 1973;32(4):913-
6. PMID: 4751922

46. Weinstein SP, Conant EF, Orel SG, Lawton TJ, Acs G. Diabetic mastopathy in men: imaging findings in two patients. Radiology. 2001;219(3):797-9. DOI: 10.1148/radiology.219.3.r01jn38797 PMID: 11376272

47. Joshi MG, Lee AK, Loda M, Camus MG, Pedersen C, Heatley GJ, et al. Male breast carcinoma: an evaluation of prognostic factors contributing to a poorer outcome. Cancer. 1996;77(3):490-8. DOI: 10.1002/(SICI) 1097-0142(199602 01) 77:3<490::AID-CNCR10>3.0.CO;2-\# PMID: 8630956

48. McLachlan SA, Erlichman C, Liu FF, Miller N, Pintilie M. Male breast cancer: an 11 year review of 66 patients. Breast Cancer Res Treat. 1996;40(3):225-30. PMID: 8883964

49. Taneja P, Maglic D, Kai F, Zhu S, Kendig RD, Fry EA, et al. Classical and Novel Prognostic Markers for Breast Cancer and their Clinical Significance. Clinical Medicine Insights Oncology. 2010;4:15-34. PMID: PMC2883240

50. Chen W, Huang Y, Lewis GD, Szeja SS, Hatch SS, Farach A et al. Treatment Outcomes and Prognostic Factors in Male Patients With Stage IV Breast Cancer: A Population-based Study. Clin Breast Cancer. 2017. DOI: 10.1016/j.clbc.2017.07.005 PMID: 28888581 